\title{
Desempenho econômico do consórcio de coentro com beterraba, adubados com doses de jitirana, combinada com esterco bovino
}

\section{Economic performance of coriander consortium with beet fertilized with doses of jitirana, combined with manure}

\author{
Whenia Benevides Ramalho ${ }^{1}$; Paulo César Ferreira Linhares ${ }^{2}$; Patrício Borges Maracajá ${ }^{3}$; Alany Moisa Bezerra de Almeida ; \\ Ana Paula Morais ${ }^{5}$
}

Resumo: A análise econômica ajuda a interpretar os resultados obtidos nos diferentes sistemas de cultivo e deve ser empregada indicando o que e como plantar, de maneira a gerar lucro ao produtor. A utilização da mistura de adubos orgânicos constitui-se em alternativa para os agricultores que produzem em sistema agroecológico, pois contribui para a redução dos custos de produção e maior eficiência no uso dos insumos disponíveis na área. Diante do exposto, objetivou-se avaliar o desempenho econômico do consórcio de coentro com beterraba, adubados com doses de jitirana, combinada com esterco bovino. O experimento foi conduzido na Fazenda Experimental Rafael Fernandes, distrito de Alagoinha, zona rural de Mossoró - RN, no período de setembro a dezembro de 2014. O delineamento experimental utilizado foi de blocos completos casualizados com os tratamentos arranjados em esquema fatorial 2 x 5, com três repetições. O primeiro fator foi constituído pelo cultivo solteiro e consorciado do coentro e da beterraba. $\mathrm{O}$ segundo fator, pelas doses de jitirana, combinada com esterco bovino $\left(0,0 ; 1,0 ; 2,0 ; 3,0\right.$ e 4,0 $\mathrm{kg} \mathrm{m}^{-2}$ de canteiro). As características avaliadas para os indicadores econômicos foram: renda bruta e renda líquida, taxa de retorno e índice de lucratividade. O melhor desempenho econômico do sistema foi obtido na dose de 4,0 $\mathrm{kg} \mathrm{m}^{-2}$ de canteiro, com renda bruta de $\mathrm{R} \$ 14.940,00$; custo de produção de $\mathrm{R} \$ 3.306,00$; renda líquida de $\mathrm{R} \$ 11.634,00$; taxa de retorno $\mathrm{R} \$ 4,52$; índice de lucratividade de $77,87 \%$, para uma área de produção de $900 \mathrm{~m}^{2}$.

Palavras-chave: Produção agroecológica. Indicadores econômicos. Beta Vulgaris L. Coriandrum sativum L.

Abstract: The economic analysis helps to interpret the results obtained in different farming systems and should be employed indicating what and how to plant, in order to generate profit to the producer. The use of the mixture of organic fertilizers is up alternative for farmers who produce in agroecological system, it contributes to the reduction of production costs and more efficient use of inputs available in the area. Given the above, aimed to evaluate the economic performance of coriander consortium with beet fertilized with doses of jitirana, combined with manure. The experiment was conducted at the Experimental Farm Rafael Fernandes, Alagoinha district, a rural area of Mossoró - RN, from September to December 2014. The experimental design was a randomized complete block with treatments arranged in a factorial $2 \mathrm{x} 5$, with three replications. The first factor was constituted by monocropping and intercropping coriander and beet. The second factor, the dosages of jitirana combined with manure $(0,0 ; 1,0 ; 2,0 ; 3,0$ and 4,0 kg m-2 site). The characteristics evaluated for economic indicators were gross income and net income, rate of return and profitability index. The improved economic performance of the system was obtained at a dose of $4.0 \mathrm{~kg} \mathrm{~m}-2$ site, with gross income of $\mathrm{R} \$ 14,940.00$; production cost of $\mathrm{R} \$ 3,306.00$; net income of $\mathrm{R} \$ 11,634.00$; return rate of $\mathrm{R} \$ 4.52$; of $77.87 \%$ profitability index to a $900 \mathrm{~m} 2$ production area.

Key words: Agro-ecological production. Economic indicators. Beta Vulgaris L. Coriandrum sativum L.

\footnotetext{
*Autor para correspondência

Recebido para publicação em 07/01/2016; aprovado em 08/03/2016

${ }^{1}$ Engenheira agrônoma, Mestre em Sistemas Agroindustriais. E-mail:whenia_benevides@hotmail.com

${ }^{2}$ Engenheiro Agrônomo, Doutor em Agronomia- Pesquisador da Universidade Federal Rural do Semi-Árido (UFERSA) E-mail: paulolinhares@ufersa.edu.br; paulojitirana@yahoo.com.br.

${ }^{3}$ D. Sc. Prof. Associado IV. Curso de Pós-graduação em Sistemas Agroindustriais do CCTA/UFCG/Pombal - PB. E-mail: patriciomaracaja@ gmail.com

${ }^{4}$ Engenheira agrônoma, Mestranda em Sistemas Agroindustriais, Universidade Federal de Campina Grande, E-mail: alanymoisa1@ @hotmail.com

${ }^{5}$ Engenheira agrônoma, Mestranda em Sistemas Agroindustriais, Universidade Federal de Campina Grande, E-mail: anapaula_mn@ @otmail.com.
} 


\section{INTRODUÇÃO}

A agricultura orgânica constitui-se nos dias de hoje, a atividade agrícola de maior crescimento no mundo. Neste sistema, há o aproveitamento integral e racional de todos os recursos disponíveis dentro da propriedade rural. Uma opção viável para os que labutam na produção orgânica de hortaliças consiste da utilização de materiais prontamente disponíveis na propriedade, o que contribui para a diminuição dos custos de produção.

Esse sistema, segundo Pereira (2014) torna-se mais eficiente em termos de aquisição e utilização de adubos, quando se faz uso da mistura de materiais com potencial para serem utilizados como adubo na produção orgânica de hortaliças. Nesse contexto, a jitirana constitui-se em espécie promissora, tendo em vista sua qualidade nutricional e produção de fitomassa verde e seca, correspondendo a 36000 e $4000 \mathrm{~kg} \mathrm{ha}^{-1}$ respectivamente, e teor de nitrogênio de $26,2 \mathrm{~g}$ $\mathrm{kg}^{-1}$ (LINHARES et al., 2008), com relação C/N de 18/1, o que viabiliza a espécie para uso como adubo verde pela rápida decomposição da biomassa. Outro recurso disponível nas propriedades são os estercos (bovino e caprino), que constitui uma alternativa de adubação para ser utilizado misturado com outra fonte rica em nutrientes que possibilitem que as culturas atendam as suas necessidades nutricionais.

Um modelo de cultivo bastante eficaz para esse sistema de produção, praticado há muito tempo e encontrado em todas as partes do mundo, é o cultivo consorciado. Que se trata do cultivo simultâneo de duas ou mais espécies em uma mesma área, por um período comum do ciclo das mesmas, podendo ser semeadas simultaneamente ou não. Além de utilizar eficientemente a terra, possui melhor cobertura do solo devido ao maior adensamento das plantas, reduzindo consequentemente a incidência de plantas daninhas, pragas, doenças e possibilitando um aumento na renda líquida aos agricultores (CARRILHO, 2013).

Entre as hortaliças produzidas em sistema consorciado encontra-se o coentro e a beterraba. O coentro (Coriandrum sativum L.) é uma olerícola de considerável valor e importância em diversas regiões do Brasil, especialmente nas regiões Norte e Nordeste, onde é muito consumido e presente na alimentação diária (FILGUEIRA, 2008). Em relação a beterraba ( Beta vulgaris L.), a planta tem porte reduzido e, cuja parte comestível comercializada é a sua raiz de sabor adocicado e cor vermelho-arroxeada, sua produção ainda é restrita e pouco expressiva no Rio Grande do Norte, com produção pequena, havendo a necessidade de importação de outras regiões (GRANGEIRO et al., 2007).

A maioria das tecnologias desenvolvidas para a agricultura familiar visa aumentar a produtividade da terra, eliminar a ociosidade da área ou ter um maior aproveitamento do espaço (FUKUSHI, 2012). Nesse sentido, um importante aspecto a ser considerado quando se estuda a produção orgânica de hortaliças em sistema consorciado, consiste no aproveitamento de recursos disponíveis na propriedade que garantam uma maior rentabilidade para o produtor em um menor espaço, garantindo um rápido retorno dos investimentos.

Considerando a importância social econômica, Brochardt (2004) afirma que para a quantificação dos insumos e serviços componentes de um sistema produtivo, uma planilha de custos permite ao produtor rural investir de modo a obter o maior retorno financeiro e um melhor aproveitamento de insumos e serviços regionais, com menos impacto ecológico, junto com uma correta avaliação dos preços de mercado e do potencial de comercialização, permitindo assim ao produtor gerenciar de forma otimizada o empreendimento. A análise econômica ajuda a interpretar os resultados obtidos nos diferentes sistemas de cultivo e deve ser empregada, tendo o objetivo de auxiliar os agricultores na tomada de decisões, sobretudo no que se refere ao que plantar e como plantar (ZANATTA, SCHIOCCHET; NADAL, 1993).

Diante do exposto, objetivou-se avaliar o desempenho econômico do consórcio de coentro com beterraba, adubados com doses de jitirana, combinada com esterco bovino.

\section{MATERIAL E MÉTODOS}

O experimento foi realizado na Fazenda Experimental Rafael Fernandes, localizada no distrito de Alagoinha, zona rural de Mossoró-RN, no período de setembro a dezembro de 2014, em solo classificado como Latossolo Vermelho Amarelo Argissólico franco arenoso (EMBRAPA, 2006). O distrito de Lagoinha está situado nas seguintes coordenadas: latitude 5o03'37'S e longitude de 37o23'50"W Gr, com altitude de aproximada de $72 \mathrm{~m}$, distando $20 \mathrm{~km}$ da cidade de Mossoró-RN. Segundo Thornthwaite, o clima local é DdAa', ou seja, semi-árido (CARMO FILHO; ESPÍNOLA SOBRINHO; MAIA NETO, 1991).

Antes da instalação do experimento foram retiradas amostras de solo na profundidade de $0-20 \mathrm{~cm}$, as quais foram secas ao ar e peneirada, em seguida foram analisadas, obtendo-se os seguintes resultados: $\mathrm{pH}$ (água 1:2,5) =6,5; $\mathrm{Ca}$ $=1,1 \mathrm{cmolc} \mathrm{dm}^{-3} ; \mathrm{Mg}=0,6 \mathrm{cmolc} \mathrm{dm}^{-3} ; \mathrm{K}=40 \mathrm{mg} \mathrm{dm}^{-3} ; \mathrm{Na}$ $=6,0 \mathrm{mg} \mathrm{dm}^{-3} ; \mathrm{P}=12,0 \mathrm{mg} \mathrm{dm}^{-3}$ extrator Mehlich ${ }^{-1}$ e M.O. $=$ $0,55 \%$.

O experimento foi conduzido no delineamento de blocos completos casualizados em esquema fatorial $2 \times 5$, com três repetições. O primeiro fator foi constituído pelo cultivo solteiro e consorciado do coentro e da beterraba, sendo o segundo fator pelas doses de jitirana combinado com esterco bovino $\left(0,0 ; 1,0 ; 2,0 ; 3,0\right.$ e 4,0 $\mathrm{kg} \mathrm{m}^{-2}$ de canteiro).

Tabela 1. Identificação dos tratamentos. Mossoró-RN, UFERSA, 2015.

\begin{tabular}{ccc}
\hline Tratamentos & Sistema de cultivo & $\begin{array}{c}\text { Doses (jitirana }+ \\
\text { esterco)** }\end{array}$ \\
\hline T1 & Consórcio $(\mathrm{C}+\mathrm{B}) *$ & 0,0 \\
T2 & Consórcio $(\mathrm{C}+\mathrm{B})$ & 1,0 \\
T3 & Consórcio $(\mathrm{C}+\mathrm{B})$ & 2,0 \\
T4 & Consórcio $(\mathrm{C}+\mathrm{B})$ & 3,0 \\
T5 & Consórcio $(\mathrm{C}+\mathrm{B})$ & 4,0 \\
T6 & Monocultivo coentro & 0,0 \\
T7 & Monocultivo coentro & 1,0 \\
T8 & Monocultivo coentro & 2,0 \\
T9 & Monocultivo coentro & 3,0 \\
T10 & Monocultivo coentro & 4,0 \\
T11 & Monocultivo beterraba & 0,0 \\
T12 & Monocultivo beterraba & 1,0 \\
T13 & Monocultivo beterraba & 2,0 \\
T14 & Monocultivo beterraba & 3,0 \\
T15 & Monocultivo beterraba & 4,0 \\
\hline
\end{tabular}

*Consórcio de coentro(C) com beterraba(B). **Doses de jitirana mais esterco bovino em $\mathrm{Kg} \mathrm{m}^{-2}$ de canteiro. 
Utilizou-se a proporção de 1:1, ou seja, uma parte de jitirana para uma parte de esterco bovino. O espaçamento utilizado para o coentro em sistema de consórcio foi de $0,20 \mathrm{x}$ $0,05 \mathrm{~m}$ com cinco plantas cova ${ }^{-1}$. Já, em cultivo solteiro o coentro foi semeado no espaçamento $0,10 \mathrm{~m} \times 0,05 \mathrm{~m}$, com cinco plantas $\operatorname{cova}^{-1}$ (LINHARES et al., 2014), perfazendo uma população de 1000 plantas $\mathrm{m}^{-2}$ de canteiro. A beterraba foi plantada nas entrelinhas do coentro no espaçamento de 0,10 m entre plantas, com uma planta cova ${ }^{-1}$.

A área total no arranjo foi de $1,44 \mathrm{~m}^{2}$ e a área útil de $1,00 \mathrm{~m}^{2}$, contendo 50 plantas de beterraba e 400 plantas de coentro para o cultivo consorciado. Para a beterraba plantouse a cultivar "Early Wonder", e para o coentro, plantou a cultivar "verdão", que é bastante utilizado por agricultores da região.

A jitirana foi coletada da vegetação nativa nas proximidades do campus da UFERSA, no início do período da floração, quando a planta apresenta o máximo de concentração de nutrientes. As plantas foram trituradas em máquina forrageira convencional, obtendo-se segmentos entre 2,0 e 3,0 cm. Estas foram secas ao sol e acondicionado em sacos de ráfia permanecendo com umidade média de $10 \%$, armazenada nas instalações da UFERSA, em ambiente seco adequado para a conservação de material fenado. Por ocasião da instalação do experimento (03/09/2014) foram retiradas cinco amostras de jitirana, encaminhada para o laboratório de fertilidade do solo e nutrição de plantas do Departamento de Ciências Ambientais e Tecnológicas da UFERSA para as análises de carbono $(\mathrm{C})$; nitrogênio $(\mathrm{N})$; fósforo $(\mathrm{P})$; potássio $\left(\mathrm{K}^{+}\right)$; cálcio $\left(\mathrm{Ca}^{2+}\right)$; magnésio $\left(\mathrm{Mg}^{2+}\right)$ e relação carbono/nitrogênio. Para a jitirana (Merremia aegyptia) os resultados foram: $570 \mathrm{~g} \mathrm{~kg}^{-1} \mathrm{C} ; 25,0 \mathrm{~g} \mathrm{~kg}^{-1} \mathrm{~N} ; 12,5 \mathrm{~g} \mathrm{kpg}^{-1} \mathrm{P}$; $18,0 \quad \mathrm{~g} \mathrm{~kg}^{-1} \mathrm{~K} ; 12,0 \mathrm{~g} \mathrm{~kg}^{-1} \mathrm{Ca} ; 16,0 \mathrm{~g} \mathrm{~kg}^{-1} \mathrm{Mg}$ e relação/carbono nitrogênio (23/1). Quantificados em função da matéria seca, levando em consideração os $10 \%$ de umidade, sendo incorporado na camada de $0-20 \mathrm{~cm}$ do solo.

O esterco bovino utilizado foi proveniente da criação de novilhas do setor de bovinocultura da UFERSA, criadas no sistema intensivo, alimentadas com concentrado e tendo como volumoso, o capim canarana (Echinocloa polystochya (Kunth) Hitchc.). Por ocasião da instalação do experimento foram retiradas cinco amostras do montante de esterco utilizado, encaminhadas para o laboratório de fertilidade do solo e nutrição de plantas do Departamento de Ciências Ambientais e Tecnológicas da UFERSA para as análises de $\mathrm{pH}$, nitrogênio $(\mathrm{N})$, matéria orgânica $(\mathrm{MO})$, fósforo $(\mathrm{P})$, potássio $\left(\mathrm{K}^{+}\right)$, sódio $\left(\mathrm{Na}^{+}\right)$, cálcio $\left(\mathrm{Ca}^{2+}\right)$ e magnésio $\left(\mathrm{Mg}^{2+}\right)$. Apresentou como resultados os seguintes valores: ( $\mathrm{pH}$ (água $1: 2,5)=8,06 ; 19,74 \mathrm{~g} \mathrm{~kg}^{-1}$ de $\mathrm{N} ; 87,92 \mathrm{~g} \mathrm{~kg}^{-1}$ de MO; 767,7 $\mathrm{mg} \mathrm{dm}^{-3}$ de P; 6827,5 $\mathrm{mg} \mathrm{dm}^{-3} \mathrm{de} \mathrm{K}^{+} ; 2449,8 \mathrm{mg} \mathrm{dm}^{-3} \mathrm{de} \mathrm{Na}^{+}$;

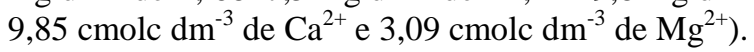

O preparo do solo da área experimental consistiu de uma gradagem seguida de levantamento dos canteiros, utilizando como ferramenta manual a enxada. As irrigações foram efetuadas por microaspersão, com turno de rega diária parcelada em duas aplicações (manhã e tarde). Como tratos culturais, foram realizadas duas capina manual e uma amontoa na beterraba. A incorporação foi realizada dezesseis dias antes a semeadura. Durante o período de permanência dos resíduos no solo, antecedendo a semeadura, fizeram-se irrigações com a finalidade de manter a umidade do solo a $70 \%$ da capacidade de campo, sendo essa, uma condição ideal para o processo de nitrificarão (NOVAIS, 2007).

O plantio das culturas ocorreu no mesmo dia (19/09/2014), segundo recomendação de Grangeiro et al. (2011). Essas culturas apresentam ciclos diferentes (85 dias da semeadura até a colheita para a beterraba e de 30 a 35 dias da semeadura até a colheita para o coentro). O desbaste da beterraba e do coentro ocorreu aos 15 dias após a semeadura para ambas as culturas.

A colheita da beterraba foi realizada aos 80 dias após a semeadura em 09/12/2014. Já o coentro foi colhido aos 34 dias após a semeadura em 23/10/2014. Quando as mesmas atingiram o seu ponto de colheita.

Para a validação do uso de jitirana combinado com esterco bovino no consórcio de coentro com beterraba foi realizada pela determinação dos indicadores econômicos que constituíram da renda bruta (Foi obtida multiplicando-se a produtividade da cultura de cada tratamento pelo valor do produto pago ao produtor, conforme levantamento feito na região de Mossoró-RN no mês de janeiro 2015, que foi de $\mathrm{R} \$$ 1,00 o molho coentro e $\mathrm{R} \$ 2,00 \mathrm{um} \mathrm{kg}$ de beterraba, expressa em reais), renda líquida (Foi obtida subtraindo-se da renda bruta dos custos de produção. Foram considerados os preços de insumos e serviços vigentes no mês de janeiro de 2015, na cidade de Mossoró-RN.), taxa de retorno (Foi obtida por meio da relação entre a renda bruta e o custo de produção de cada tratamento) e índice de lucratividade (Foi obtido da relação entre a renda líquida e a renda bruta, expresso em porcentagem).

Duas análises de variância univariada foram usadas: uma para avaliar as características econômicas do coentro no delineamento em blocos casualizados em esquema fatorial 2 sistema de cultivo (solteiro e consorciado) x 5 (Cinco doses da combinação de jitirana com esterco bovino) e a outra para as características econômicas da beterraba em cultivo solteiro e consorciado sob doses da combinação de jitirana com esterco bovino, em esquema fatorial 2 x 5 . O aplicativo utilizado foi o ESTAT (KRONKA; BANZATO, 1995). O procedimento de ajustamento de curva de resposta para o fator quantitativo (Cinco doses da combinação de jitirana com esterco bovino) foi realizado através do Software Table Curve (JANDEL SCIENTIFIC, 1991) e, para o fator qualitativo (cultivo solteiro e consorciado do coentro e da beterraba) foi utilizado o teste de Tukey ao nível de $5 \%$ de probabilidade para se realizar as comparações entre os sistemas de cultivo. As funções respostas foram avaliadas com base nos seguintes critérios: lógica biológica, significância do quadrado médio do resíduo da regressão (QMRr), alto valor do coeficiente de determinação (R2), significância dos parâmetros da regressão, utilizando-se o teste $\mathrm{t}$ ao nível de $1 \%$ de probabilidade.

\section{RESULTADOS E DISCUSSÃO}

Os indicadores econômicos da eficiência do consórcio de coentro com beterraba fertilizado com a combinação de doses de jitirana mais esterco bovino incorporado ao solo encontram-se (Tabela 2 e 3 ). 
Tabela 2 - Indicadores econômicos de renda bruta (RB), custo de produção $(\mathrm{CP})$, renda líquida (RL), taxa de retorno (TR) e índice de lucratividade (IL), para a produção do consorcio de coentro com beterraba em função da combinação de doses de jitirana com esterco bovino incorporado ao solo em uma área de $900 \mathrm{~m}^{2}$. Pombal-PB, UFCG. 2015.

\begin{tabular}{cccccc}
\hline FT (Fatores-tratamentos) & RB (R\$) & CP (R\$) & RL (R\$) & TR (R\$) & IL $(\%)$ \\
\hline 0,0 kg J + EST & $3.456,00$ & $3.306,00$ & 150,00 & 4,04 & 4,34 \\
1,0 kg J + EST & $7.722,00$ & $3.306,00$ & $4.416,00$ & 2,34 & 57,20 \\
2,0 kg J + EST & $10.440,00$ & $3.306,00$ & $7.134,00$ & 3,16 & 68,30 \\
3,0 kg J + EST & $12.420,00$ & $3.306,00$ & $9.114,00$ & 3,76 & 73,38 \\
$4,0 \mathrm{~kg} \mathrm{~J}+$ EST & $14.940,00$ & $3.306,00$ & $11.634,00$ & 4,52 & 77,87 \\
\hline
\end{tabular}

FT (Fatores-tratamentos); PD (Produção de coentro em kg m-2 de canteiro); PP (Preço pago pelo consumidor por molho de coentro e de rabanete); RB (Renda bruta, que consiste na multiplicação do preço pago pelo consumidor vezes a produção); CP (Custo de produção por canteiro de 900 m2); RL (Renda liquida que consiste em subtrair a renda bruta do custo de produção); TR (Taxa de retorno, indica o que o produtor terá para cada real investido, foi obtida por meio da relação entre a renda bruta e o custo total de cada tratamento) e IL (Índice de lucratividade indica em termos percentuais o retorno do investimento, foi obtido pela relação entre a renda líquida e a renda bruta, multiplicado por 100 e expresso em porcentagem).

Tabela 3 - Indicadores econômicos de renda bruta (RB), custo de produção (CP), renda líquida (RL), taxa de retorno (TR) e índice de lucratividade (IL), para a beterraba consorciada com coentro e coentro consorciado com beterraba em função de diferentes doses de jitirana combinado com esterco bovino incorporado ao solo $\mathrm{em} \mathrm{kg} \mathrm{m}^{-2}$ de canteiro e no número de molhos de coentro $\mathrm{m}^{-2}$ de canteiro (A1) e por área de $900 \mathrm{~m}^{2}$ (A2). Pombal-PB, UFCG. 2015.

\begin{tabular}{|c|c|c|c|c|c|c|c|c|}
\hline FT (Fatores tratamentos) & A1 & $\mathrm{A} 2$ & $\mathrm{PP}(\mathrm{R} \$)$ & $\mathrm{RB}(\mathrm{R} \$)$ & $\mathrm{CP}(\mathrm{R} \$)$ & $\mathrm{RL}(\mathrm{R} \$)$ & $\mathrm{TR}(\mathrm{R} \$)$ & $\operatorname{IL}(\%)$ \\
\hline \multicolumn{9}{|c|}{ BETERRABA CONSORCIADO COM COENTRO } \\
\hline $0,0 \mathrm{~kg} \mathrm{~J}+\mathrm{EST}$ & 0,28 & 252 & 3,00 & 756,00 & $3.306,00$ & $-2.550,00$ & 0,22 & $-337,3$ \\
\hline $1,0 \mathrm{~kg} \mathrm{~J}+\mathrm{EST}$ & 0,86 & 774 & 3,00 & $2.322,00$ & $3.306,00$ & $-984,00$ & 0,70 & $-42,4$ \\
\hline $2,0 \mathrm{~kg} \mathrm{~J}+\mathrm{EST}$ & 1,20 & 1080 & 3,00 & $3.240,00$ & $3.306,00$ & $-66,00$ & 0,98 & $-2,03$ \\
\hline $3,0 \mathrm{~kg} \mathrm{~J}+\mathrm{EST}$ & 1,60 & 1440 & 3,00 & $4.320,00$ & $3.306,00$ & $1.014,00$ & 1,31 & 23,5 \\
\hline $4,0 \mathrm{~kg} \mathrm{~J}+\mathrm{EST}$ & 2,20 & 1980 & 3,00 & $5.940,00$ & $3.306,00$ & $2.634,00$ & 1,80 & 44,3 \\
\hline \multicolumn{9}{|c|}{ COENTRO CONSORCIADO COM BETERRABA } \\
\hline $0,0 \mathrm{~kg} \mathrm{~J}+\mathrm{EST}$ & 3 & 2700 & 1,00 & $2.700,00$ & $3.306,00$ & $-606,00$ & 0,82 & $-22,4$ \\
\hline $1,0 \mathrm{~kg} \mathrm{~J}+\mathrm{EST}$ & 6 & 5400 & 1,00 & $5.400,00$ & $3.306,00$ & $2.094,00$ & 1,63 & 38,8 \\
\hline $2,0 \mathrm{~kg} \mathrm{~J}+\mathrm{EST}$ & 8 & 7200 & 1,00 & $7.200,00$ & $3.306,00$ & $3.894,00$ & 2,17 & 54,1 \\
\hline $3,0 \mathrm{~kg} \mathrm{~J}+\mathrm{EST}$ & 9 & 8100 & 1,00 & $8.100,00$ & $3.306,00$ & $4.794,00$ & 2,45 & 59,2 \\
\hline $4,0 \mathrm{~kg} \mathrm{~J}+\mathrm{EST}$ & 10 & 9000 & 1,00 & $9.000,00$ & $3.306,00$ & $5.694,00$ & 2,72 & 63,3 \\
\hline
\end{tabular}

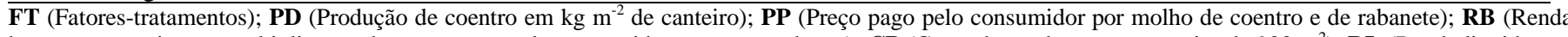
bruta, que consiste na multiplicação do preço pago pelo consumidor vezes a produção); $\mathbf{C P}$ (Custo de produção por canteiro de $900 \mathrm{~m}^{2}$ ); RL (Renda liquida que consiste em subtrair a renda bruta do custo de produção); TR (Taxa de retorno, indica o que o produtor terá para cada real investido, foi obtida por meio da relação entre a renda bruta e o custo total de cada tratamento) e IL (Índice de lucratividade indica em termos percentuais o retorno do investimento, foi obtido pela relação entre a renda líquida e a renda bruta, multiplicado por 100 e expresso em porcentagem).

Tabela 4 - Coeficientes de custos de produção de uma área de $900 \mathrm{~m}^{2}$, cultivado com coentro consorciado com beterraba adubado com doses de jitirana combinado com esterco bovino. Pombal-PB, UFCG. 2015.

\begin{tabular}{|c|c|c|c|c|}
\hline DISCRIMINAÇÃ̃O & UND & QT & $\mathbf{P R}(\mathbf{R} \$)$ & Total $(\mathbf{R} \$)$ \\
\hline \multicolumn{5}{|l|}{ I - Insumos } \\
\hline Semente: beterraba (Early Wonder) & $\mathrm{Kg}$ & 05 & 90,00 & 450,00 \\
\hline Semente: coentro (Verdão) & $\mathrm{Kg}$ & 04 & 14,00 & 56,00 \\
\hline Esterco bovino na dose de $2,0 \mathrm{~kg} \mathrm{~m}-2$ de canteiro & $\mathrm{Kg}$ & 1800 & 0,20 & 360,00 \\
\hline Sub-Total I & & & & 866,00 \\
\hline Corte da jitirana na dose $2,0 \mathrm{~kg} \mathrm{~m}-2$ de canteiro & $\mathrm{d} / \mathrm{h}$ & 05 & 40,00 & 200,00 \\
\hline Trituração manual das espécies & $\mathrm{d} / \mathrm{h}$ & 03 & 40,00 & 120,00 \\
\hline Secagem & $\mathrm{d} / \mathrm{h}$ & 03 & 40,00 & 120,00 \\
\hline Limpeza da área & $\mathrm{d} / \mathrm{h}$ & 02 & 40,00 & 80,00 \\
\hline Confecção de canteiros & $\mathrm{d} / \mathrm{h}$ & 03 & 40,00 & 120,00 \\
\hline Distribuição e incorporação da jitirana mais esterco bovino & $\mathrm{d} / \mathrm{h}$ & 04 & 40,00 & 160,00 \\
\hline Plantio da beterraba e coentro & $\mathrm{d} / \mathrm{h}$ & 02 & 40,00 & 80,00 \\
\hline Desbaste & $\mathrm{d} / \mathrm{h}$ & 04 & 40,00 & 160,00 \\
\hline Capina manual & $\mathrm{d} / \mathrm{h}$ & 03 & 40,00 & 120,00 \\
\hline Bombeamento da água de irrigação & $\mathrm{Kw} / \mathrm{h}$ & & & 40,00 \\
\hline Bomba de irrigação $3 / 4$ & Und & 01 & 200,00 & 200,00 \\
\hline Microaspessores & Und & 100 & 2,00 & 200,00 \\
\hline Mangueira de irrigação (100 m) & Rolo & 07 & 40,00 & 280,00 \\
\hline Colheita do coentro e do rabanete & $\mathrm{d} / \mathrm{h}$ & 07 & 40,00 & 280,00 \\
\hline Comercialização do coentro e do rabanete & $\mathrm{d} / \mathrm{h}$ & 07 & 40,00 & 280,00 \\
\hline Total (II) & & & & $2.440,00$ \\
\hline Total (I + II) & & & & $\mathbf{3 . 3 0 6 , 0 0}$ \\
\hline
\end{tabular}

Foi verificado aumento da renda bruta á medida em que foram adicionadas as diferentes doses de jitirana mais esterco bovino, sendo que a renda máxima foi de $\mathrm{R} \$ 14.940,00$ com a dose de $4,0 \mathrm{~m}^{-2}$ de canteiro de jitirana mais esterco bovino (Figura 1). Esse valor obtido esta dentro do padrão de 
produção orgânica, sendo de grande importância para os agricultores que labutam na produção orgânica de hortaliças.

A renda liquida teve comportamento semelhante, onde o melhor rendimento foi obtido na dose de $4,0 \mathrm{~kg} \mathrm{~m}^{-2}$ de canteiro de jitirana mais esterco bovino, com valor médio de $\mathrm{R} \$ 11.940,00$, taxa de retorno de $\mathrm{R} \$ 4,52$ e índice de lucratividade de $77,87 \%$ (Figuras $2 ; 3$ e 4). A lucratividade representa, em percentual, o rendimento real obtido com a comercialização de certo produto, ou seja, é quanto o produtor tem de renda, após serem descontados os custos de produção. O objetivo principal da produção agrícola é maximizar lucros, com minimização de custos, então, ao planejar a produção agrícola não se deve pensar apenas em otimizar a produção em determinada condição de cultivo, mas também na alocação adequada de recursos disponíveis que viabilizem a implantação de uma determinada cultura.

Figura 1. Renda bruta do consórcio de coentro com beterraba fertilizada com a combinação de doses de jitirana com esterco bovino incorporado ao solo. Pombal-PB, UFCG, 2015.

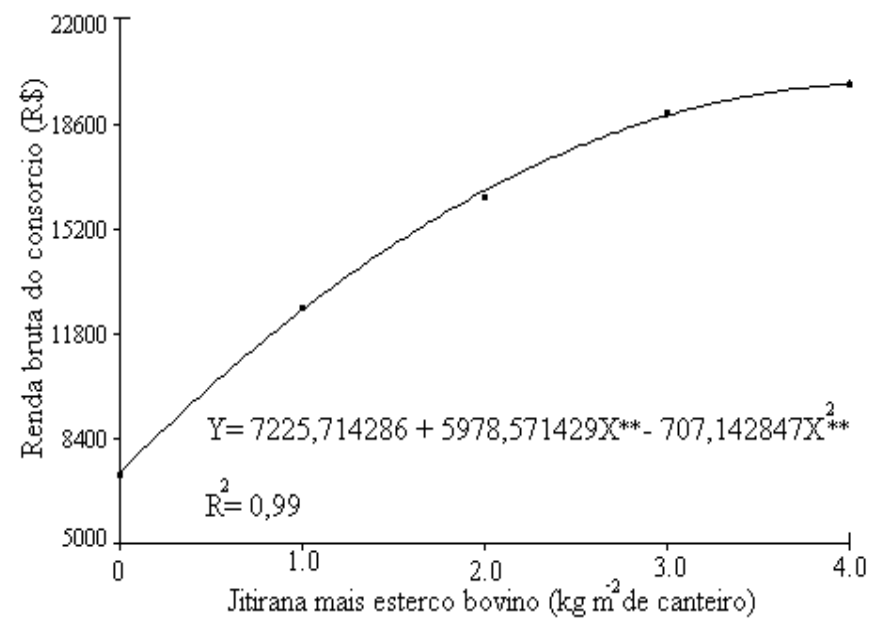

Figura 2. Renda líquida do consórcio de coentro com beterraba adubado com doses de jitirana combinado com esterco bovino incorporado ao solo. Pombal-PB, UFCG, 2015.

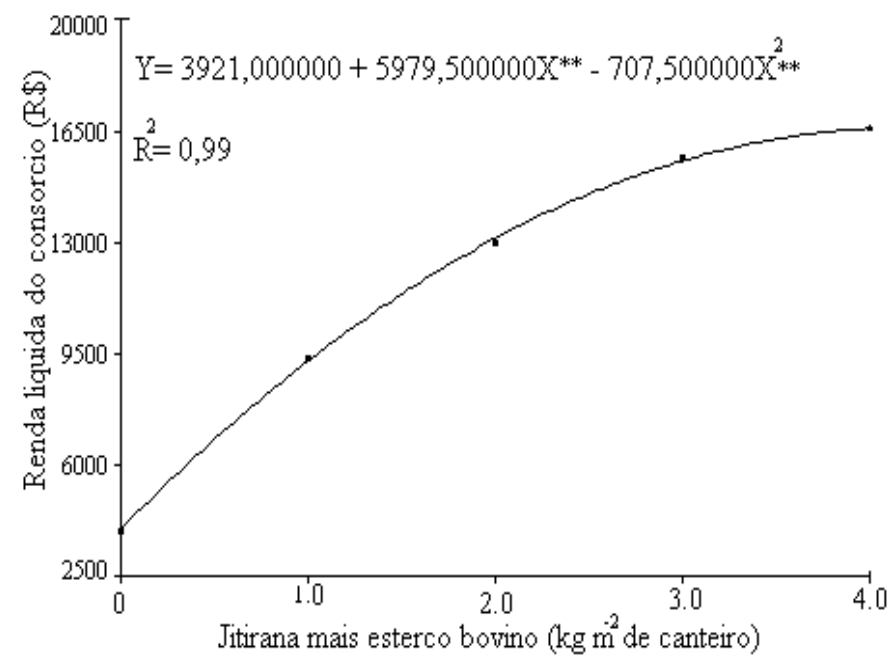

\section{CONCLUSÕES}

O melhor desempenho econômico do sistema foi obtido na dose de 4,0 $\mathrm{kg} \mathrm{m}^{-2}$ de canteiro, com renda bruta de $\mathrm{R} \$$ $14.940,00$, renda líquida de $\mathrm{R} \$ 11.634,00$ taxa de retorno de $\mathrm{R} \$ 4,52$ e índice de lucratividade de 77,87\%.

\section{REFERÊNCIAS BIBLIOGRÁFICAS}

BROCHARDT, I. Desenvolvimento de metodologia para elaboração de custos de produção das principais culturas exploradas em Santa Catarina. Florianópolis: Instituto CEPA, 2004. 67 p.

CARMO FILHO, F. do; ESPÍNOLA SOBRINHO, J. .; MAIA NETO, J. M. Dados climatológicos de Mossoró: um município semiárido nordestino. Mossoró: ESAM, 121p. (Coleção mossoroense, série C, 30). 1991. 
CARRILHO, A.J. Produção e análise bromatológica de repolho e rabanete em consórcio. Monografia. Brasília: Faculdade de Agronomia e Medicina Veterinária, Universidade de Brasília, 2013, 29 p.

EMPRESA BRASILEIRA DE PESQUISA AGROPECUÁRIA - EMBRAPA. Sistema brasileiro de classificação de solos. 2.ed. Rio de Janeiro: Embrapa, 2006. $306 \mathrm{p}$.

FILGUEIRA, F.A.R. Novo Manual de Olericultura: Agrotecnologia moderna na produção e comercialização de hortaliças. Viçosa: UFV. 2008. 402 p.

FUKUSHI, Y. K. M. Manejo de plantas espontâneas em sistemas consorciados de hortaliças. (Monografia). Brasília: Faculdade de Agronomia e Medicina Veterinária, Universidade de Brasília. 27 p, 2012.

GRANGEIRO, L.C.; SANTOS, A.P.; FREITAS, F.C.L.; SIMÃO, L.M.C.; BEZERRA NETO, F.; Avaliação agroeconômica das culturas da beterraba e coentro em função da época de estabelecimento do consórcio. Revista Ciência Agronômica, Fortaleza, v. 42, n. 1, p. 242-248, 2011.

GRANGEIRO, L. C.; NEGREIROS, M. Z.; SOUZA, B. S.; AZEVEDO, P. E.; OLIVEIRA, S. L.; MEDEIROS, M. A. Acúmulo e exportação de nutrientes em beterraba. Ciência e Agrotecnologia, Lavras, v.31, p.267-273, 2007.

JANDEL SCIENTIFIC. Table curve: curve fitting software. Corte Madera, CA: Jandel Scientific, 1991. 280p.
KRONKA, S. N.; BANZATO, D. A. Estat: sistema para análise estatística versão 2. Jaboticabal: Funep, 3. ed. 1995. $243 \mathrm{p}$.

LINHARES, P. C. F.; OLIVEIRA, J. D. de.; PEREIRA, M. F. S.; FERNANDES, J. P. P.; DANTAS, R. P. Espaçamento para a cultura do coentro adubado com palha de carnaúba nas condições de Mossoró-RN. Revista verde, Pombal, v.9, n.3, p.01-06, 2014.

LINHARES, P. C. F.; LIMA, G. K.L; MADALENA. J. A. da S.; MARACAJÁ, P. B.; FERNANDES, P. L. de O. Adição de jitirana ao solo no desempenho de rúcula cv. Folha Larga. Revista Caatinga, Mossoró, v.21, n.5, p.89-94, 2008.

NOVAIS, R. F. Fertilidade do solo. In: MEURER, E. J. Fatores que influenciam o crescimento e o desenvolvimento das plantas. Viçosa: SBCS, p. 65-90, 2007.

PEREIRA, B. B. M. Eficiência agroeconômica de cultivares de coentro consorciado com rabanete adubado com jitirana mais esterco bovino. Dissertação (Mestrado em sistemas agroindustriais) - Universidade Federal de Campina Grande (UFCG), Pombal, 2014, 65p.

ZANATTA, J. C.; SCHIOCCHET, M.A. ; NADAL, R. Mandioca consorciada com milho, feijão ou arroz de sequeira no Oeste Catarinense. Florianópolis: Empresa de Pesquisa Agropecuária e Difusão de Tecnologia de Santa Catarina S. Boletim Técnico. 36p. 1993. 